\title{
Detecção do Grapevine virus $A$ e Grapevine virus $B$ por Hibridização "Dot-Blot" com Sondas Moleculares Não Radioativas*
}

\author{
Andreia E. Moreira ${ }^{1}$, José O. Gaspar ${ }^{1 * *}$ \& Hugo Kuniyuki ${ }^{2 * *}$ \\ ${ }^{1}$ Departamento de Zoologia e Botânica, Instituto de Biociências, Letras e Ciências Exatas-Universidade Estadual Paulista \\ (IBILCE-UNESP), CEP 15054-000, São José do Rio Preto, SP, e-mail: gaspar@ibilce.unesp.br; ${ }^{2}$ Intituto Agronômico de \\ Campinas (IAC) -Centro de Pesquisa e Desenvolvimento de Fitossanidade, CEP 13020-902, Campinas, SP
}

(Aceito para publicação em 13/12/2004)

Autor para correspondência: José Osmar Gaspar

MOREIRA, A.E., GASPAR, J.O. \& KUNIYUKI, H. Detecção do Grapevine virus A e Grapevine virus B por hibridização “dot-blot" com sondas moleculares não radioativas. Fitopatologia Brasileira 30:538-542. 2005.

\section{RESUMO}

O vírus A da videira (Grapevine virus A, GVA) e o vírus B da videira (Grapevirus virus B, GVB) estão associados à acanaladura do lenho de Kober ("Kober stem grooving") e ao fendilhamento cortical da videira ("grapevine corky bark"), respectivamente. Este trabalho descreve o uso de sondas moleculares de cDNA na detecção de isolados do GVA (GVA-SP) e do GVB (GVB-C-SP e GVB-I-SP) em videiras (Vitis spp.) e fumo (Nicotiana occidentalis). As sondas marcadas com digoxigenina foram produzidas por RT-PCR utilizando oligonucleotídeos específicos para os genes da proteína capsidial. Os RNA totais foram extraídos de 45 plantas de diversas variedades de videira e de 13 plantas de fumo inoculadas mecanicamente com o GVB. Os RNA extraídos das plantas infetadas, indexadas biologicamente, hibridizaram com as sondas, não se verificando reação com plantas sadias. Para confirmar os resultados de hibridização, foram também feitos testes de RT-PCR. A utilização de hibridização "dot-blot" com sondas de cDNA mostrou-se eficaz na detecção dos vírus com especificidade e sensibilidade, ressaltando-se que, preferencialmente, folhas maduras e ramos dormentes devem ser utilizados nos testes diagnósticos para o GVB e GVA, respectivamente.

Palavras-chave adicionais: Vitis, Vitivirus, fendilhamento cortical da videira, "grapevine cork barky", acanaladura do lenho de Kober, "Kober stem grooving".

\begin{abstract}
Detection of Grapevine virus $A$ and Grapevine virus $B$ by dot blot hybridization with non-radioactive molecular probes

Grapevine virus $A(\mathrm{GVA})$ and Grapevine virus $B(\mathrm{GVB})$ are involved in the Kober stem grooving and grapevine corky bark diseases, respectively. This work reports the molecular detection of isolates of GVA (GVA-SP) and GVB (GVB-CSP and GVB-I-SP) in grapevines (Vitis spp.) and tobacco (Nicotiana occidentalis) by non-radioactive molecular probes. The digoxigenin-labeled probes were generated by RT-PCR using specific primers to the coat protein genes. Total RNA was extracted from 45 plants of several grapevine varieties and from 13 plants of tobacco mechanically inoculated with GVB. The RNA extracted from infected plants, considered infected by biological indexing, reacted to the cDNA probes while there was no hybridization with healthy plants. These results were also confirmed by RT-PCR experiments. The use of the cDNA probes hybridization was proved to be efficient in detecting both GVA and GVB with high specificity and sensitivity. However, mature leaves and dormant cuttings should be preferably used in diagnostic tests of GVB and GVA, respectively.
\end{abstract}

Additional keywords: Vitis, Vitivirus, stem grooving, grapevine cork barky, Kober stem grooving.

Entre as principais viroses da videira (Vitis spp.) que ocorrem no Brasil, destaca-se o complexo do lenho rugoso ("grapevine rugose wood complex"), termo usado para descrever um grupo de doenças caracterizadas por alterações no lenho de variedades sensíveis do gênero Vitis (Minafra, 2000). Incluídos nesse complexo, encontram-se o fendilhamento cortical ou intumescimento dos ramos ("Grapevine Corky Bark", GCB) e a acanaladura do lenho de Kober (“Kober Stem Grooving”, KSG) (Kuniyuki \& Costa, 1982; Kuhn, 1992), duas viroses de ampla distribuição, encontradas em quase todos os países que cultivam a videira

\footnotetext{
* Apoio FAPESP

** Bolsista do CNPq
}

(Martelli et al., 1997).

As principais características do GCB são fendilhamento no córtex, avermelhamento das folhas de variedades tintas de Vitis vinifera L., redução no vigor e produção escassa ou nula dependendo da variedade (Kuniyuki \& Costa, 1982; Kuhn, 1992). O agente etiológico do GCB tem aproximadamente $800 \mathrm{~nm}$ de comprimento e é denominado vírus B da videira (Grapevine virus B, GVB, gênero Vitivirus, família Flexiviridae) (Martelli et al., 1997; Adams et al., 2004). No Brasil, o GVB ocorre com incidência de até $20 \%$ nos vinhedos do Estado de São Paulo (Kuniyuki \& Costa, 1982) e superior a $60 \%$ em algumas plantações no Rio Grande do Sul (Kuhn, 1992). Nos vinhedos de São Paulo 
dois isolados desse vírus foram identificados: o isolado comum (GVB-C-SP) e o isolado Itália (GVB-I-SP) que são sorologicamente relacionados, mas apresentam sintomas distintos (Kuniyuki et al., 2000), estando o gene da proteína capsidial de ambos já seqüenciado (Moreira et al., 2004a).

No KSG, os sintomas consistem em acanaladuras ou longos sulcos no lenho da variedade de porta-enxerto Kober 5BB. A maioria das variedades de copa e de porta-enxerto de videira não apresenta sintomas visíveis da infecção, podendo a doença ser identificada pela enxertia nesse portaenxerto indicador. A doença é atribuída ao vírus A da videira (Grapevine virus A, GVA), gênero Vitivirus, família Flexiviridae (Adams et al., 2004), com partículas filamentosas de cerca de $800 \mathrm{~nm}$ de comprimento. No Brasil, o GVA ocorre com incidência de $6,1 \%$ a $8,6 \%$ no Rio Grande do Sul (Fajardo et al., 2004) e em torno de $11 \%$ nos vinhedos paulistas (Kuniyuki et al. 1997). O gene da proteína capsidial do isolado paulista do GVA (GVA-SP) já foi seqüenciado mostrando alta identidade com isolados da África do Sul e Itália (Moreira et al., 2004b).

Tanto o GVA como o GVB são vírus restritos ao floema da videira, única hospedeira natural, apresentam distribuição irregular nos tecidos e uma concentração que aumenta durante o período vegetativo, atingindo o máximo no outono, sendo ainda baixa a ponto de dificultar a detecção por métodos de laboratório (Minafra, 2000). Estas características, associadas ao fato de serem pouco imunogênicos, dificultam a detecção por métodos sorológicos. Testes biológicos de indexação, como a enxertia em videiras indicadoras, são demasiadamente demorados uma vez que a manifestação dos sintomas ocorre entre seis e 24 meses para o GCB e entre 36 e 48 meses para o KSG (Amorim \& Kuniyuki, 1997).

Os métodos moleculares vêm se tornando de escolha para a detecção dos vírus associados ao complexo do lenho rugoso da videira, devido à maior especificidade e sensibilidade em relação aos métodos sorológicos. A técnica de PCR já foi utilizada com sucesso para a detecção de vitivírus em tecidos de herbáceas ou videiras infetadas (Minafra et al., 1992a). A utilização de sondas de ácidos nucleicos para a detecção de vírus do gênero Vitivirus constitui outra alternativa de diagnóstico molecular. Sondas marcadas radioativamente (Minafra et al., 1992b) ou com digoxigenina (Saldarelli et al., 1994) mostraram-se eficientes e apresentaram boa sensibilidade na detecção. Apesar disto, a utilização de técnicas moleculares para detecção de vírus de videira no Brasil é ainda incipiente (Fajardo et al., 2004), sendo a enxertia com videiras indicadoras o método mais freqüentemente utilizado (Kuniyuki \& Costa, 1982; Kuniyuki, et al., 1997; Kuhn, 1992; Amorim \& Kuniyuki, 1997).

O objetivo deste trabalho foi testar a hibridização "dotblot" com sondas não radioativas de cDNA como técnica alternativa para a detecção do GVA e GVB em videiras e em plantas de fumo inoculadas mecanicamente.

As amostras avaliadas consistiram de 45 plantas de diversas variedades de videiras provenientes do IAC (Centro de Pesquisa e Desenvolvimento de Fitossanidade, Setor de Virologia), das quais 35 foram testadas quanto à presença do GVB e dez quanto à presença do GVA. Essas plantas haviam sido previamente submetidas a testes de indexação biológica empregando-se a variedade LN-33 como indicadora para o fendilhamento cortical e as variedades Niagara Rosada e Kober 5BB como indicadoras para a acanaladura do lenho de Kober. Cinco plantas foram consideradas suspeitas ou possivelmente infetadas pelo fato de as indicadoras não terem apresentado sintomas típicos do fendilhamento cortical no primeiro ciclo vegetativo. As amostras foram constituídas por folhas novas e maduras coletadas de videiras em fase adiantada do ciclo vegetativo (março) e por ramos dormentes ou próximos da dormência (julho). Além disto, também foram testadas 13 plantas de fumo (Nicotiana occidentalis Wheeler) inoculadas mecanicamente com o isolado GVB-C-SP, mediante fricção de extratos de pecíolos e nervuras de folhas de videiras infetadas em presença de tampão fosfato $\mathrm{pH} 7,0$ contendo $2,5 \%(\mathrm{v} / \mathrm{v})$ de nicotina.

De todas as amostras foi extraído RNA total utilizando-se o método de MacKenzie et al. (1997). Os tecidos (1g) foram congelados em $\mathrm{N}_{2}$ líquido, triturados a pó e misturados com 5,0 ml de tampão (isotiocianato de guanidina $4 \mathrm{M}$, acetato de sódio $0,2 \mathrm{M} \mathrm{pH} 5,0$, EDTA $25 \mathrm{mM}$ e PVP-40 2,5\%), 0,5 $\mathrm{ml}$ de Sarcosil 20\% (p/v) e 0,05 $\mathrm{ml}$ de 2mercaptoetanol. A mistura foi aquecida a $70{ }^{\circ} \mathrm{C}$ por $10 \mathrm{~min}$, resfriada à temperatura ambiente e centrifugada a $10.000 \mathrm{~g} /$ 15 min com coleta do sobrenadante e adição de igual volume de isopropanol para precipitação dos ácidos nucleicos. Após incubação por 10 min a temperatura ambiente, o RNA total foi recuperado por centrifugação a $10.000 \mathrm{~g} / 10 \mathrm{~min}$ e ressuspendido em $100 \mu \mathrm{l}$ de tampão desnaturante (MOPS $0,02 \mathrm{M}$, formamida $67 \%$ (v/v) e formaldeído $2,5 \mathrm{M}$ ).

As sondas não radioativas de DNA foram produzidas por RT-PCR com incorporação ao acaso do esteróide digoxigenina (DIG-dUTP; Boehringer Mannheim) e utilizando oligonucleotídeos complementares ao RNA do GVB ou GVA cujas seqüências são as seguintes: GVB: 5' CAAGCAATTCCCCGAGAGT 3' (senso) e 5' TTTAGCCG CACTCCTT GACT 3' (antisenso) (nucleotídeo 6425 ao 7118) (acesso GenBank: X754480); GVA: 5' GACAAATG GCACACTAGG 3' (senso) e 5' AAGCCTGACCTAGTC ATCTTGG 3' (antisenso) (nucleotídeo 6409 ao 6839) (acesso GenBank: X75433). A PCR constou de uma desnaturação inicial a $94{ }^{\circ} \mathrm{C}$ por 4 min, seguida de 30 ciclos com desnaturação a $94^{\circ} \mathrm{C}$ por $1 \mathrm{~min}$, anelamento a $45^{\circ} \mathrm{C}(\mathrm{GVB})$ ou $53{ }^{\circ} \mathrm{C}$ (GVA) por 1 min e extensão a $72^{\circ} \mathrm{C}$ por $2 \mathrm{~min}$, com uma extensão final a $72^{\circ} \mathrm{C}$ por $10 \mathrm{~min}$.

Para a hibridização "dot-blot", os RNA extraídos (1g/ $100 \mu \mathrm{l})$ foram desnaturados $\left(55^{\circ} \mathrm{C}\right.$ por $10 \mathrm{~min}$ e resfriamento imediato em gelo/álcool por $5 \mathrm{~min}$ ) e aplicados em membrana de náilon (Hybond-N+; Amersham Biosciences) com a utilização do aparelho "Bio-dot" conforme especificação do fabricante (Bio-Rad). A pré-hibridização foi conduzida a 50 ${ }^{\circ} \mathrm{C}$ por $1 \mathrm{~h}$ em solução contendo SDS $7 \%(\mathrm{p} / \mathrm{v})$, fosfato de 
sódio $0,05 \mathrm{M} \mathrm{pH} \mathrm{7,0,} \mathrm{formamida} \mathrm{50 \%} \mathrm{(v/v),} \mathrm{reagente}$ bloqueador 2\% (p/v) (Boehringer Mannhein), SSC 5X (SSC $1 \mathrm{X}=$ citrato de sódio $0,03 \mathrm{M} \mathrm{pH} \mathrm{7,0;} \mathrm{NaCl} 0,3 \mathrm{M}$ ) e $\mathrm{N}-$ lauroylsarcosina $0,1 \%(\mathrm{p} / \mathrm{v})$. Em seguida, procedeu-se a hibridização com as respectivas sondas diluídas na solução de pré-hibridização a $50{ }^{\circ} \mathrm{C}$ por $20 \mathrm{~h}$. Seguiram-se lavagens com SSC $2 \mathrm{X}$ contendo $\operatorname{SDS} 0,1 \%(2 \times 5 \mathrm{~min} /$ temperatura ambiente) e SSC $1 \mathrm{X}$ contendo SDS 0,1\% (2 x $\left.15 \mathrm{~min} / 68^{\circ} \mathrm{C}\right)$. A detecção foi feita com anti-soro anti-digoxigenina conjugado com fosfatase alcalina, substrato quimioluminescente (CDP-Star, Amersham-Pharmacia) e exposição em filme de raio $\mathrm{X}$ por $20 \mathrm{~min}$.

Foram usados como controles positivos plasmídeos recombinantes contendo fragmentos amplificados do genoma do GVA ou GVB (região da proteína capsidial) (Moreira et al., 2004a, b).

Oito amostras (quatro para o GVA e quatro para o GVB) também foram testadas por RT-PCR, seguindo-se as condições descritas por Moreira et al. $(2004 \mathrm{a}, \mathrm{b})$ e com os mesmos oligonucleotídeos utilizados para a produção da sonda.

Os resultados da hibridização "dot-blot" estão apresentados na Figura 1. Para avaliar a especificidade das sondas, foram feitos testes de hibridização utilizando a sonda produzida para o GVA com ácidos nucleicos de planta infetada com o GVA (videira 2*: 'Kober 5BB'/'Niagara'), com o GVB (videira 2: 'Niagara Branca') e com o vírus associado ao lenho estriado de Rupestris (Rupestris stem pitting associated virus, RSPaV) gênero Foveavirus (variedade Brasil). Um "dot-blot" similar foi hibridizado com a sonda produzida para o GVB. As sondas mostraram-se específicas, hibridizando somente com o respectivo RNA complementar (Figura 1A e 1B).

Para o GVB, observou-se que quando as amostras de tecidos utilizadas para extração de RNA foram obtidas de folhas maduras de videira, a hibridização foi verificada em um número maior de amostras (Figura 1C) e os dados foram concordantes com os resultados da indexação biológica (Tabela 1). No entanto, quando folhas novas das mesmas plantas foram utilizadas, houve hibridização em poucas amostras sugerindo uma baixa concentração viral ou ausência do vírus em folhas jovens de videira (dados não mostrados). Também foram realizados testes para a detecção do GVB com tecidos dos ramos, sendo obtidos resultados similares aos de hibridização utilizando folhas maduras (dados não mostrados).

Nos testes para o GVA, a utilização de amostras de tecidos de folhas, tanto novas quanto maduras, não foi eficiente para a detecção do vírus (dados não mostrados). Somente quando foram utilizadas amostras de tecidos dos ramos (região do floema) é que se obteve hibridização detectável (Figura 1D).

Esses resultados podem ser explicados em função da baixa concentração e distribuição irregular de ambos os vírus
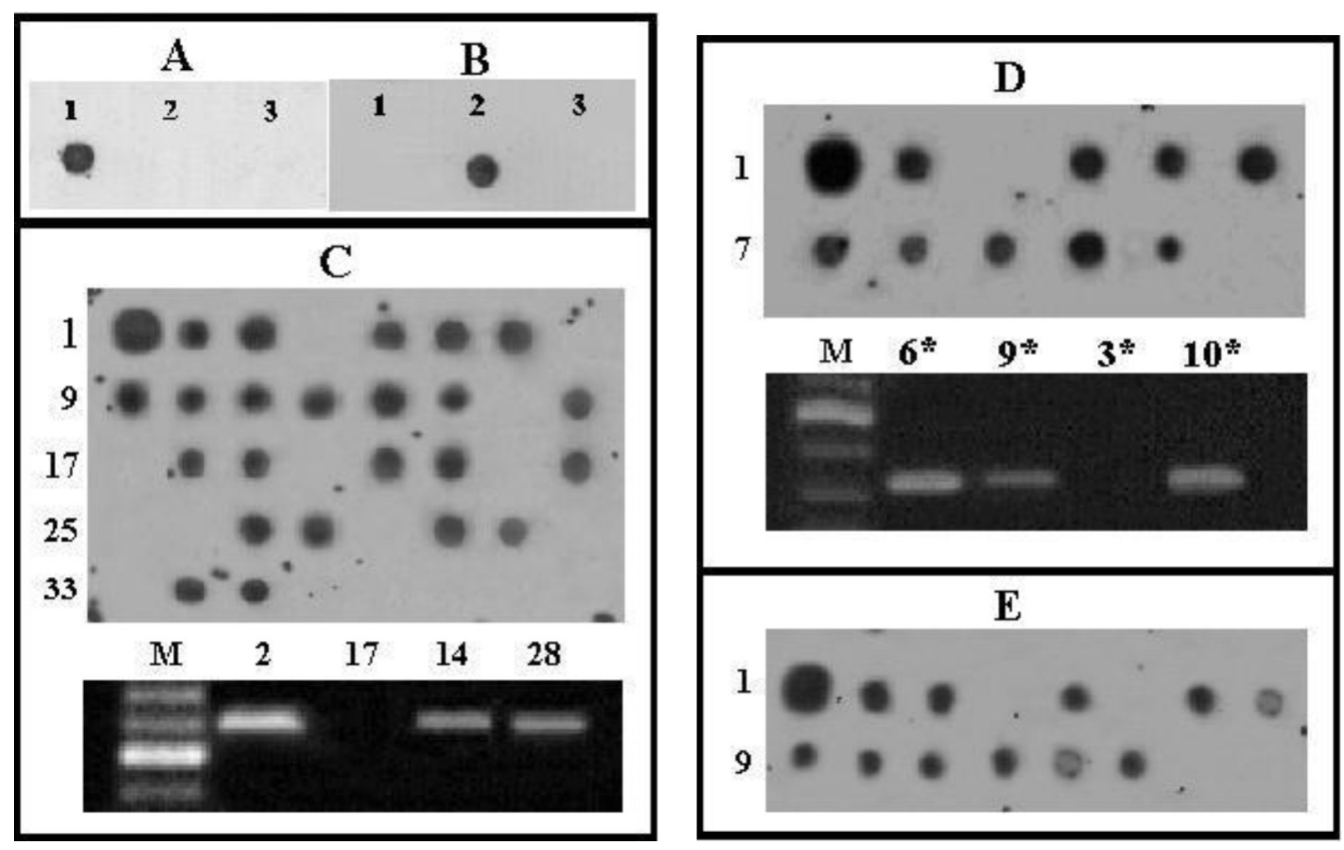

FIG. 1 - Hibridização "dot-blot” com sonda para o Grapevine virus A (GVA) (A) e Grapevine virus B (GVB) (B) em RNA total extraído de videira (Vitis spp.) infetada com GVA (1), GVB (2) e Rupestris stem pitting associated virus (RSPaV) (3). C: Hibridização "dot blot" (sonda para o GVB) com RNA total extraído de folhas maduras de videira e análise dos produtos amplificados por RT-PCR (abaixo do "dot"). D: Hibridização "dot blot” (sonda para o GVA) com RNA total extraído de ramos dormentes de videira e análise dos produtos amplificados por RT-PCR (abaixo do "dot”). Os números das figuras C e D referem-se às variedades listadas nas tabelas 1 e 2. E: Hibridização "dot-blot" de Nicotiana occidentalis inoculadas mecanicamente com o GVB, 1: controle positivo, amostra 15: planta sadia. 
nos tecidos da planta, sendo estas características ainda mais acentuadas em relação ao GVA (Minafra, 2000). Dessa forma, para otimizar os testes de detecção por sonda, deve-se utilizar, preferencialmente, folhas maduras para a detecção do GVB e ramos dormentes ou próximos da dormência para a detecção do GVA. Em períodos de dormência da videira, os ramos também podem ser utilizados para a detecção do GVB com eficiência comparável às folhas maduras.

Os resultados de hibridização com as sondas foram, em geral, concordantes com aqueles fornecidos pela indexação biológica (Tabelas 1 e 2), sendo possível detectar os dois isolados do GVB e o GVA e também determinar o

TABELA 1 - Detecção do Grapevine virus B (GVB) por hibridização em amostras indexadas para o fendilhamento cortical (GCB) por teste biológico

\begin{tabular}{|c|c|c|c|}
\hline $\mathbf{N}^{0}$ & Variedade de Vitis spp. & $\begin{array}{l}\text { Indexação } \\
\text { Biológica* }\end{array}$ & Hibridização \\
\hline 1 & Controle positivo: gene da $\mathrm{CP}$ & - & + \\
\hline 2 & Niagara Branca (22.7954) & $\mathrm{GCB}-\mathrm{C}$ & + \\
\hline 3 & Niagara Bran ca (22.7953) & $\mathrm{GCB}-\mathrm{C}$ & + \\
\hline 4 & Niagara Branca (AG 1264) & Sadia & - \\
\hline 5 & Rubi (22.7349) & GCB-C & + \\
\hline 6 & Seibel 2 (SR 1644) & GCB -C & + \\
\hline 7 & Seibel 2 (SR 1642) & GCB-C & + \\
\hline 8 & Rupestris du Lot (VT 13) & Sadia & - \\
\hline 9 & Niagara Rosada (17.1044) & GCB -C & + \\
\hline 10 & Niagara Rosada (22.7951) & $\begin{array}{l}\text { Possivelment e } \\
\text { infet ada }\end{array}$ & + \\
\hline 11 & Niagara Branca (22.6354) & GCB-C & + \\
\hline 12 & Cardinal (17.1038) & $\begin{array}{l}\text { Possivelmente } \\
\text { infetada }\end{array}$ & + \\
\hline 13 & Itália (22.7352) & GCB-C & + \\
\hline 14 & IAC 313 (VT 1766) & $\mathrm{GCB}-\mathrm{C}$ & + \\
\hline 15 & LN-33 (VT 1969 -01) & Sadia & - \\
\hline 16 & Rubi (17.1034) & $\mathrm{GCB}-\mathrm{C}$ & + \\
\hline 17 & Cardinal (Mo 1792a) & $\begin{array}{l}\text { Possivelmente } \\
\text { infetada }\end{array}$ & - \\
\hline 18 & Rupestris du Lot (22.7242) & GCB-C & + \\
\hline 19 & Itália (22.7353) & GCB-I & + \\
\hline 20 & Isabel (SR 541) & Sadia & - \\
\hline 21 & Rupestris du Lot (22.7238) & GCB-C & + \\
\hline 22 & IAC $313(22.7406)$ & $\mathrm{GCB}-\mathrm{C}$ & + \\
\hline 23 & IAC 313 (VT 1767) & Sadia & - \\
\hline 24 & Isabel (22.6363) & GCB-I & + \\
\hline 25 & Brasil (TP 1780) & $\begin{array}{l}\text { Possivelmente } \\
\text { infetada }\end{array}$ & - \\
\hline 26 & Rubi (08.1178) & Sadia & - \\
\hline 27 & Isabel (22.6364) & GCB-I & + \\
\hline 28 & Niagara Rosada (17.1044) & $\begin{array}{l}\text { Possivelmente } \\
\text { infetada }\end{array}$ & + \\
\hline 29 & Kober 5BB (AG 1267) & Sadia & - \\
\hline 30 & Rupestris du Lot/It ália (22.6276) & GCB-I & + \\
\hline 31 & Rupestris du Lot/It ália (22.6277) & GCB-I & + \\
\hline 32 & LN-33 (08.2565) & Sadia & - \\
\hline 33 & Itália (seedling 01/96) & Sadia & - \\
\hline 34 & Rupestris du Lot/Rubi (22.7369) & GCB-I & + \\
\hline 35 & Rupestris du Lot/Brasil (22.7368) & GCB-I & + \\
\hline 36 & Brasil (seedling 01/03) & Sadia & - \\
\hline
\end{tabular}

*GCB-C: infetada pelo isolado comum; GCB-I: infetada pelo isolado Itália; +: presença de hibridização; -: ausência de hibridização estado fitossanitário das cinco plantas suspeitas de infecção. As amostras 17 e 25, que foram determinadas como possivelmente infetadas por GVB no teste biológico não produziram hibridização. Além disso, um dado discordante foi observado: a videira 9* (Kober 5BB/SR 01), considerada sadia por meio dos testes da indexação biológica, apresentou hibridização "dot-blot" com a sonda para o GVA. Para confirmar alguns resultados de hibridização, foram realizadas reações por RT-PCR com essa amostra discordante e com outras amostras selecionadas aleatoriamente, totalizando oito amostras, quatro testadas para a presença do GVA e quatro para o GVB (Figura 1C e 1D). Os resultados do RT-PCR confirmaram aqueles da hibridização, mostrando a eficácia da sonda na detecção viral. A videira 9* apresentou amplificação por RT-PCR, concordando com os dados obtidos nos testes de hibridização e confirmando a infecção da planta pelo GVA. Essa planta está sendo observada e, provavelmente, virá manifestar os sintomas da doença nos próximos ciclos vegetativos.

A sonda também foi eficiente para a detecção viral em $N$. occidentalis inoculada mecanicamente com o GVBC-SP, sendo o vírus detectado em 11 das 13 plantas inoculadas, não havendo reação com a planta sadia utilizada como controle (Figura 1E). Assim sendo, das 13 plantas inoculadas duas não foram infetadas (E4 e E6). Isso permite que a sonda também possa ser utilizada para testar e selecionar plantas herbáceas infetadas mecanicamente.

A utilização de sondas de ácidos nucleicos para a detecção de vírus do gênero Vitivirus já havia sido relatada com sucesso (Minafra et al., 1992b; Saldarelli, 1994). No entanto, em ambos os casos, foram verificados a interferência de substâncias inibidoras presentes na videira, como os taninos, o que requeria passos adicionais de purificação dos ácidos nucleicos. A metodologia para a detecção por sondas, apresentada nesse trabalho, dispensou o uso de colunas de afinidade que poderiam elevar os custos de aplicação da sonda

TABELA 2 - Detecção do Grapevine virus A (GVA) por hibridização em amostras de videira (Vitis spp.) indexadas para a acanaladura do lenho de Kober (KSG) por teste biológico

\begin{tabular}{clcc}
\hline \hline $\mathbf{N}^{0}$ & Var iedade de Vitis spp. & $\begin{array}{r}\text { Indexação } \\
\text { Biológica }\end{array}$ & Hibridização \\
\hline $1^{*}$ & Controle positivo: gene da CP & - & + \\
$2^{*}$ & Kober 5BB/Niagara Rosada (22.6398) & KSG & + \\
$3^{*}$ & Kober 5BB (AC 1267) & Sadia & - \\
$4 *$ & Kober 5BB/Niagara Rosada (22.6403) & KSG & + \\
$5^{*}$ & Kober 5BB/Niagara Rosada (22.6833) & KSG & + \\
$6^{*}$ & Kober 5BB/Niagara Rosada (22.6 857) & KSG & + \\
$7 *$ & Kober 5BB/Niagara Rosada (22.6858) & KSG & + \\
$8^{*}$ & Kober 5BB/Niagara Rosada (22.6866) & KSG & + \\
$9 *$ & Kober 5BB (SR 01) & Sadia & + \\
$10^{*}$ & Kober 5BB/Niagara Rosada (22.6875) & KSG & + \\
$11 *$ & IAC 766/Niagara Rosada (22.7093) & KSG & + \\
\hline
\end{tabular}

'presença de hibridização, - :ausência de hibridização. 
na análise de um grande número de amostras e, mesmo sem o uso dessas colunas, não foram verificadas interferências das substâncias inibidoras na reação.

Os métodos biológicos, com transmissão por enxertia em variedades indicadoras (Kober 5BB, Niagara Rosada e LN33), têm grande importância em programas para produzir, manter e propagar material básico livre de vírus. Entretanto, a manifestação de sintomas característicos de infecção viral pode ocorrer somente dois anos após a enxertia (Kuniyuki \& Costa, 1982; Amorim \& Kuniyuki, 1997; Minafra, 2000), o que torna o teste bastante demorado. Associado a esses programas é premente a implantação de métodos de diagnóstico rápidos e confiáveis das viroses da videira no Brasil.

As sondas produzidas apresentaram especificidade e sensibilidade na detecção do GVA e do GVB, podendo ser utilizadas como alternativa aos testes sorológicos para identificação desses vírus e para as triagens iniciais de material de videira destinado à propagação, desde que amostras adequadas sejam escolhidas para análise. A técnica de hibridização "dot-blot" utilizando essas sondas poderá ser empregada concomitante aos testes de indexação biológica por enxertia, que são ainda imprescindíveis nos programas de obtenção de material propagativo sadio de videira.

\section{REFERÊNCIAS BIBLIOGRÁFICAS}

ADAMS, M.J., ANTONIW, J.F., BAR-JOSEPH, M., BRUNT, A.A., CANDRESSE, T., FOSTER, G.D., Martelli, G.P., MILNE, R.G. \& FAUQUET, C.M. The new plant virus family Flexiviridade and assessment of molecular criteria for species demarcation. Archives of Virology 149:1045-1060. 2004.

AMORIM, L. \& KUNIYUKI, H. Doenças da videira. In: Kimati, H., Amorim, L., Bergamin, A., Camargo, L.E.A. \& Rezende, J.A.M. (Eds.) Manual de Fitopatologia: Doenças de plantas cultivadas. São Paulo. Agronômica Ceres. 1997. pp.736-757.

FAJARDO, T.V.M., SCHENATO, P.G., NICKEL, O. \& KUHN, G.B. Detecção de três vírus em videiras com sondas não radioativas. Fitopatologia Brasileira 29:S94. 2004 (Resumo).

KUHN, G.B. Intumescimento dos ramos da videira (“Corky Barky”), doença constatada no Rio Grande do Sul. Fitopatologia Brasileira 17:399-406. 1992.

KUNIYUKI, H. \& COSTA, A.S. Estudos sobre a virose fendilhamento cortical da videira em São Paulo. Fitopatologia Brasileira 7:71-81. 1982.

KUNIYUKI, H., YUKI, V.A. \& BETTI, J.A. Incidência da acanaladura do lenho de Kober em vinhedos no Estado de São Paulo. Fitopatologia Brasileira 22:337. 1997 (Resumo).

KUNIYUKI, H., REZENDE, J.A.M., KITAJIMA, E.W. \& BETTI, J.A. Detecção do Grapevine virus $B$ em videiras com a doença de fendilhamento cortical. Fitopatologia Brasileira 25:443. 2000 (Resumo).

MACKENZIE, D.J., MCLEAN, M.A., MUKERJI, S. \& GREEN, M. Improved RNA extraction for woody plants for the detection of viral pathogens by Reverse Transcription-Polymerase Chain Reaction. Plant Disease 81:222-226. 1997.

MARTELLI, G.P., MINAFRA, A. \& SALDARELLI, P. Vitivirus, a new genus of plant viruses. Archives of Virology 142:1929-1932. 1997.

MINAFRA, A., HADIDI, A. \& MARTELLI, G.P; Detection of grapevine closterovirus $\mathrm{A}$ in infected grapevine tissue by reverse transcription polymerase chain reaction. Vitis 31:221-227. 1992a.

MINAFRA, A., RUSSO, M. \& MARTELLI, G.P. Further studies on the use of molecular probes to grapevine closterovirus A. Vitis 31:87-93. 1992b.

MINAFRA, A. Rugose wood grapevines. Extended Abstracts, $13^{\text {th }}$ ICVG Conference, Adelaide, Australia, 2000, pp.30-34.

MOREIRA, A.E., GASPAR, J.O., CAMARGO, L.E.A. \& KUNIYUKI, H. Caracterização do gene da proteína capsidial de dois isolados, patologicamente distintos e sorologicamente semelhantes, do Grapevine virus $B$ em videiras no Estado de São Paulo. Fitopatologia Brasileira 29:75-80. 2004a.

MOREIRA, A.E., GASPAR, J.O., CAMARGO, L.E.A. \& KUNIYUKI, H. Caracterização do gene da proteína capsidial do Grapevine virus $A$ em videiras afetadas pela acanaladura do lenho de Kober no Estado de São Paulo. Fitopatologia Brasileira 29:205208. 2004b.

SALDARELLI, P., GUGLIELMI-MONTANO, H. \& MARTELLI, G.P. Detection of three grapevine closterolike viruses by nonradioactive molecular probes. Vitis 33:157-170. 1994. 